\title{
Effect of oil temperature on tribological behavior of a lubricated steel-steel contact
}

\author{
Zhen-bing Cai ${ }^{1,2}$, Yan Zhou ${ }^{2,3}$, Jun Qu ${ }^{2, *}$ \\ ${ }^{1}$ Tribology Research Institute, Key Lab of Advanced Technologies of Materials, Southwest Jiaotong \\ University, Chengdu, 610031, China \\ ${ }^{2}$ Materials Science and Technology Division, Oak Ridge National Laboratory, TN 37831, USA \\ ${ }^{3}$ Materials Science and Engineering, Texas A\&M University, College Station, TX 77843, USA \\ *Corresponding author: qujn@ornl.gov
}

\begin{abstract}
:
Tribological tests were conducted on an AISI A2 steel plate against an AISI 51200 steel ball lubricated by SAE 0W30 and PAO 4 cSt base oils containing no additive package. Friction and wear behaviors were evaluated at room temperature (RT, $\left.23^{\circ} \mathrm{C}\right)$ and a series of elevated temperatures $\left(75,100,125\right.$ and $\left.175^{\circ} \mathrm{C}\right)$. The steady-state friction coefficient appeared to be proportional to the oil temperature, probably because reduced oil viscosity at a higher temperature caused more surface asperity collisions. In contrast, wear results did not follow the trend: the wear rate surprisingly decreased when the oil temperature increased from RT to $75-100^{\circ} \mathrm{C}$, and then turned around to increase along with the temperature at above $100^{\circ} \mathrm{C}$. Evidentially, there are other significant factors than just the oil viscosity that influence the wear process upon the temperature change. Wear scar morphology examination and surface chemical analysis revealed an oxide-containing surface film on the wear scars and higher oxide content and larger film coverage seemed to reduce the wear rate. Therefore, the wear mechanism is proposed as a combined effect of mechanical material removal and protective surface film formation: the former largely depending on oil viscosity that is inversely proportional to the temperature and the latter involving surface and wear debris oxidation that is promoted by temperature elevation as well as the water content (up to $100^{\circ} \mathrm{C}$ ) in the oil.
\end{abstract}

Keywords: base oil; temperature; moisture; oxidation; wear mechanism; surface film 


\section{Introduction}

The key factors affecting the tribological performance of a bearing system generally include the bearing mechanical design, material compositions, mechanical properties, lubricant rheological properties, chemistry, and operation conditions. In this study, we investigated the effects of the lubricant temperature and water content on friction and wear behavior. In boundary lubrication, a high temperature reduces the oil viscosity and the mechanical strength of the lubricant film at the interface [1-3], generally leading to increased friction and wear. In addition, high temperature promotes tribochemical reactions on contact surfaces that can either be beneficial [4] (e.g., forming a stable tribofilm) or detrimental [5] (e.g., causing corrosion) to wear behavior. A temperature increase in SAE40 oil causes increases in both adhesive and corrosive wear [6]. Temperature also affects the concentration and distribution of oil contaminants, such as air, water, and particulates, which are usually unavoidable [7-9]. Three forms of water possibly exist in oil: dissolved water, emulsion, and free water. Lubricating properties of a water-oil emulsion have been reported with poorer than those of water-free oils [10]. Particularly, emulsion or free water in oil would cause more damage than does dissolved water because of the former causes higher compressibility of the oil film at the contact area and increased risk of cavitation [11]. On the other hand, the dissolved water in the lubricant, almost inevitable in most industrial applications, is known to increases oil viscosity and metal surface oxidation [12].

Here we report interesting observations of the friction and wear behavior of a steel-steel contact lubricated by two synthetic base oils at a series of test temperatures. Wear mechanisms were discussed based on the results of surface chemical analysis.

\section{Materials and methods}

Two synthetic base oils, SAE 0W30 (supplied by Chevron) and polyalphaolefins (PAO) $4 \mathrm{cSt}$ (supplied by Exxon Mobil), were used in this study. The 0W30 is a multiple-grade base oil blend, while the PAO is a single-viscosity base oil. Both products are neat hydrocarbons, though their exact chemical structures are not available (protected by non-analysis agreement). Neither contains any additive package. The oils were stored in an ambient environment for over a year, so their water contents were thought to 
have been at or near saturation. The measured water content in the $0 \mathrm{~W} 30$ oil was $\sim 2500 \mathrm{ppm}$ at room temperature, as determined using Karl Fisher titration and confirmed by weight loss using a heated vacuum. It is known that synthetic oils may contain much more water than mineral oils [13]. In one set of tests, $1 \mathrm{wt} \%$ of distilled water was added into the $0 \mathrm{~W} 30$ base oil and the mixture was shaken well to reach a stable emulsion. Viscosity measurements were performed with a falling ball viscometer (Petrolab Minivis II). Table 1 presents the densities and viscosities of the two lubricants at various temperatures. Five temperatures $\left(23,75,100,125\right.$, and $\left.175^{\circ} \mathrm{C}\right)$ were selected for $0 \mathrm{~W} 30$ and three temperatures $(23,100$, and $175^{\circ} \mathrm{C}$ ) for PAO in the tribological bench tests.

Table 1. Physical properties of the lubricants

\begin{tabular}{ccccc}
\hline Lubricant & Density & \multicolumn{3}{c}{ Viscosity (cP) } \\
\cline { 3 - 5 } & $\left(\mathrm{g} / \mathrm{ml}, 23^{\circ} \mathrm{C}\right)$ & $23^{\circ} \mathrm{C}$ & $40^{\circ} \mathrm{C}$ & $100^{\circ} \mathrm{C}$ \\
\hline SAE 0W30 base oil & 0.82 & 26.59 & 13.78 & 3.12 \\
\hline PAO 4 cSt base oil & 0.80 & 30.45 & 15.38 & 3.27 \\
\hline
\end{tabular}

Tribological tests were conducted using a ball-on-flat tribometer in a reciprocating sliding configuration (PLINT TE-77) at an oscillation frequency of $10 \mathrm{~Hz}$ with a stroke of $10 \mathrm{~mm}$. The tests were conducted under a normal load of $54 \mathrm{~N}$ for a sliding distance of $1,000 \mathrm{~m}$. A steel-steel contact was selected: (1) a grade 25 AISI 52100 bearing steel ball (Vickers hardness [HV]=976, d=10 mm, $R_{\mathrm{q}}=0.05$ $\mu \mathrm{m})$; (2) a hardened AISI A2 tool steel plate $\left(\mathrm{HV}=872, R_{\mathrm{q}}=0.18 \mu \mathrm{m}\right)$. Their roughness was measured by using a Mahr Perthometer M2 profiler. The HV was determined with a Buehler Micromet 2100 micro-indenter at a load of $100 \mathrm{~g}-\mathrm{f}$. At least two repeat tests were conducted under each condition.

The worn surfaces of both plates and balls were cleaned using isopropanol before imaging. The wear volume and scar depth and width were quantified using a Wyko NT9100 optical profiler. Wear scar morphology was inspected using an optical microscope (OM, Nikon Labophot-2) and a field-emission scanning electron microscope (SEM) (Hitachi S-4800) equipped with energy dispersive spectroscopy (EDS). Further surface chemical analysis was conducted on a Thermo Scientific K-Alpha x-ray photoelectron spectroscopy (XPS) instrument. The x-rays used were monochromatic Al-ka photons; 
photo-emitted electrons were analyzed with a hemispherical energy analyzer. Wide survey scans were collected from 0 to $1350 \mathrm{eV}$ at a pass energy of $200 \mathrm{eV}$ to determine overall elemental composition. Core level spectra were collected using a pass energy of $50 \mathrm{eV}$.

\section{Results}

Figure 1 shows the friction coefficient (COF) in the two oils at various temperatures. For both oils, increased testing temperature resulted in higher $\mathrm{COF}$, probably due to the decrease in oil viscosity leading to more frequent and more severe surface asperity contacts. The $\mathrm{COFs}$ at $175^{\circ} \mathrm{C}$ were the highest in each group. The addition of water resulted in a slight increase in COF (Fig. 1a). Each test showed a slow decrease in COF after running-in, which may have been due to the change in contact condition from point contact to more or less conformal contact during the wear process.

(a)

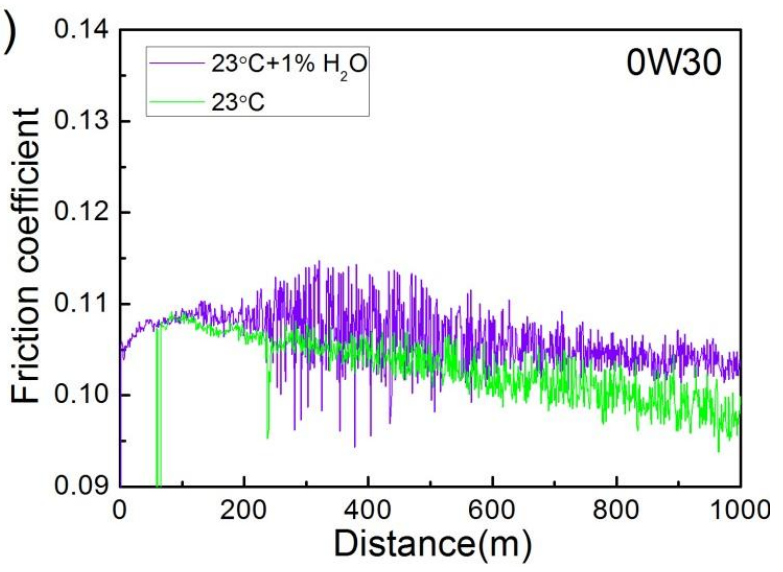

(b)

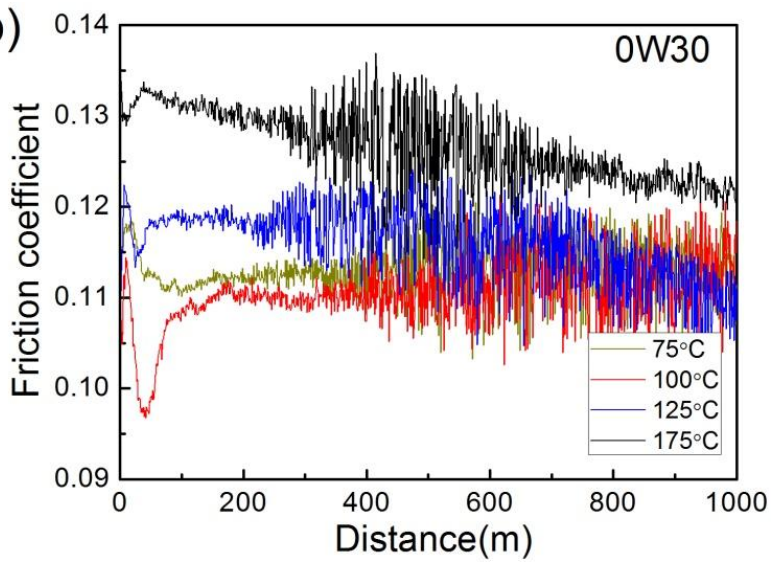




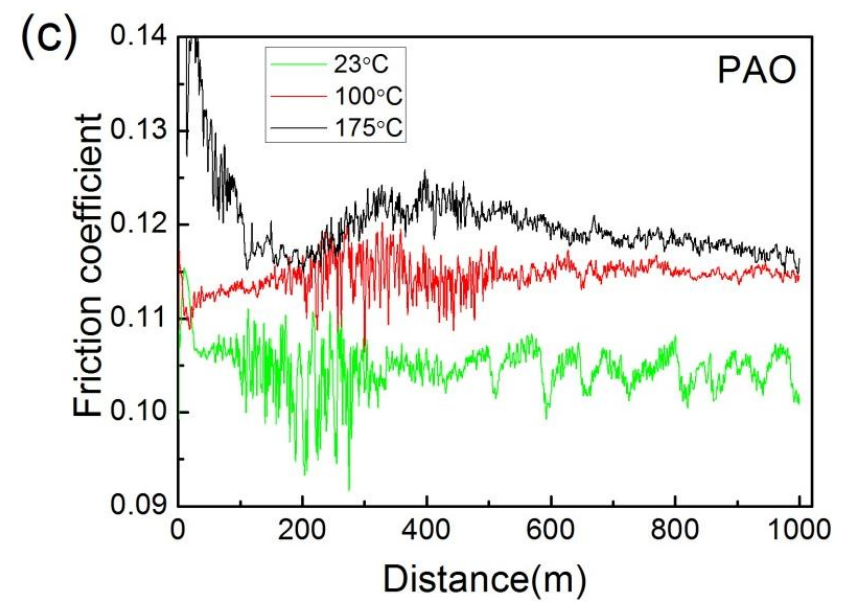

Fig. 1. Friction traces of tests in (a) $0 \mathrm{~W} 30$ at RT with and without addition of water, (b) $0 \mathrm{~W} 30$ at various temperatures from 75 to $175^{\circ} \mathrm{C}$, and (c) PAO at temperatures of 23,100 , and $175^{\circ} \mathrm{C}$.

The wear on the plates was too low to quantify. The wear rates of the balls are compared in Fig. 2; selected cross-sectional wear scar profiles (after subtracting the original ball curvature) are also shown in Fig. 2. For the tests in both oils, the wear rate had the lowest value at around $75-100^{\circ} \mathrm{C}$ and was higher at room temperature $\left(\mathrm{RT}, 23^{\circ} \mathrm{C}\right.$ ) or above $100^{\circ} \mathrm{C}$. The wear increase along with the temperature increase from 100 to $175^{\circ} \mathrm{C}$ was expected, considering the oil viscosity drop. However, the wear rate at $100^{\circ} \mathrm{C}$ was notably lower than that at RT, which is unexpected, even though the oil viscosity was one order of magnitude lower (Table 1). The addition of $1 \mathrm{wt} \%$ water to the $0 \mathrm{~W} 30$ oil caused increases in both the friction and wear rates, as shown in Fig 2.

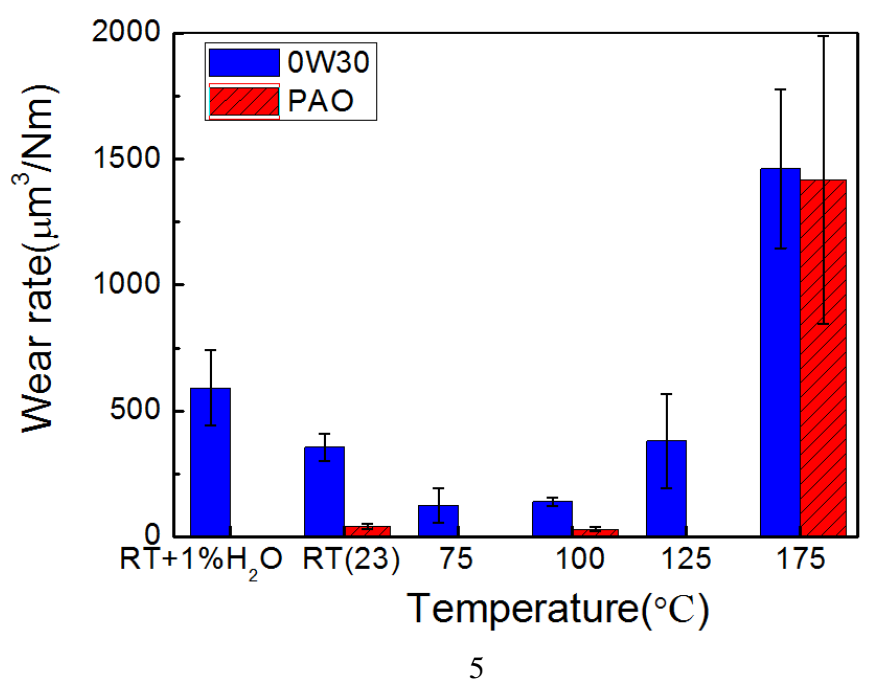


(a) Ball wear rates at various temperatures
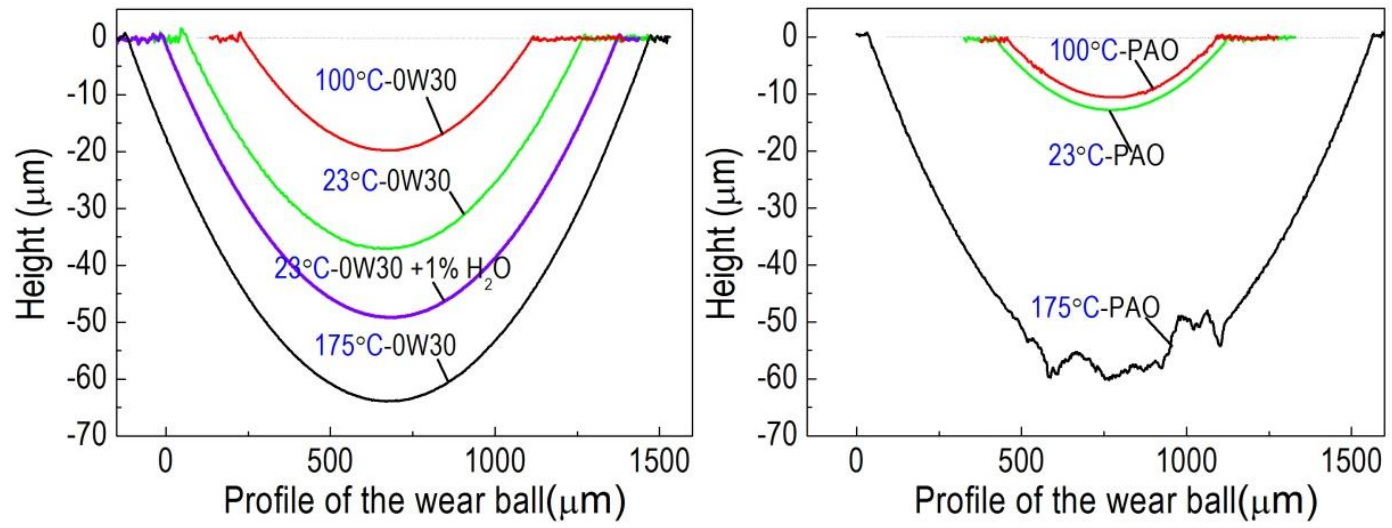

(b) Cross-sectional profiles of ball wear scars after subtracting the ball curvature: 0W30 (left) and PAO (right)

Fig. 2. Comparison of ball wear at various temperatures.

The surface morphologies of the worn surfaces of the balls and plates tested at 23,100 , and $175^{\circ} \mathrm{C}$ are presented in Fig. 3. For wear scars generated at room temperature, abrasion marks and a surface film with partial surface coverage (dark bands) were observed (Fig. 3a for 0W30 and Fig. 3e for PAO). The wear scars on both the balls and the plates produced at $100^{\circ} \mathrm{C}$ were largely covered by a surface film, as shown in Fig. 3b (OW30) and Fig. 3f (PAO). Such surface films appeared dark under an OM and seemed relatively thick and layered, as indicated by the spallation and cracking shown in the SEM images. The surface film was believed to be formed primarily by wear debris deposition and surface oxidation. At $175^{\circ} \mathrm{C}$, the wear debris film showed low coverage on wear scars (Figs. $3 \mathrm{c}$ and $3 \mathrm{~g}$ for $0 \mathrm{~W} 30$ and PAO, respectively). When $1 \mathrm{wt} \%$ of water was added to $0 \mathrm{~W} 30$ oil, the wear scars appeared to be dominated by abrasion with little wear debris deposition. 
(a)

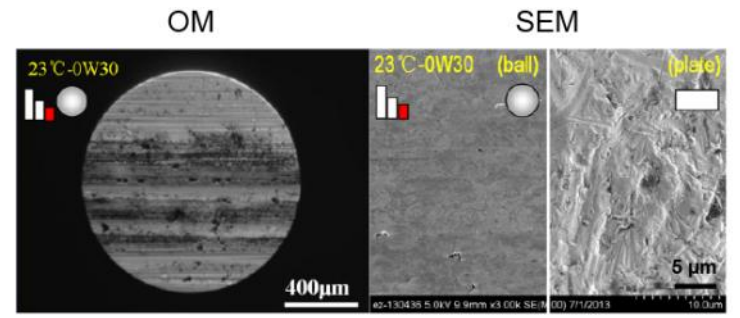

(b)

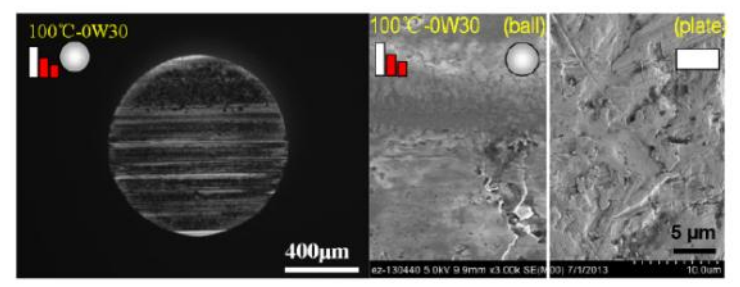

(c)

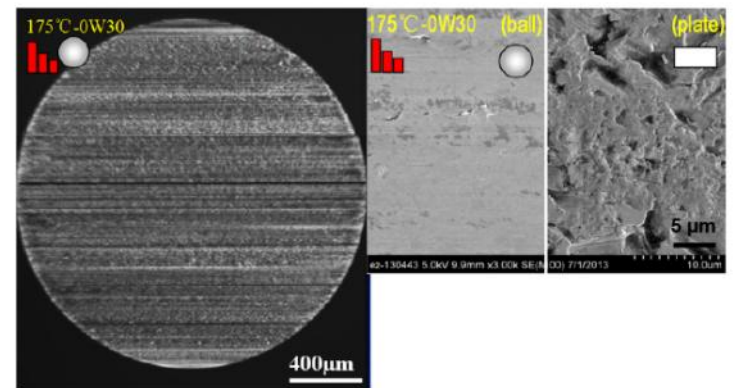

(d)

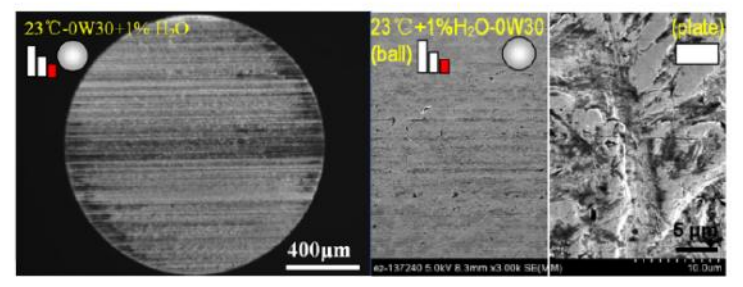

(e)

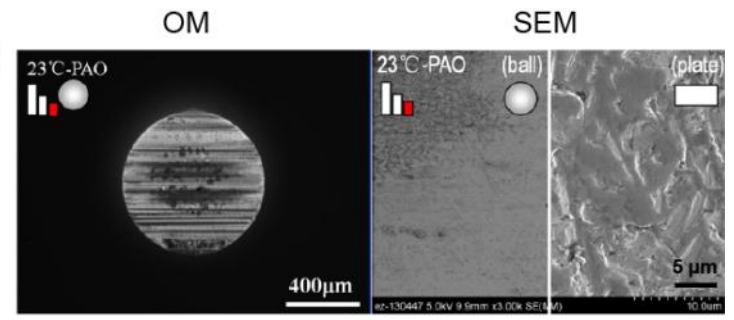

(f)

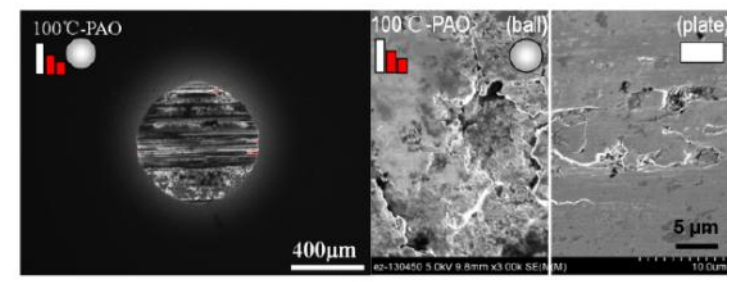

(g)

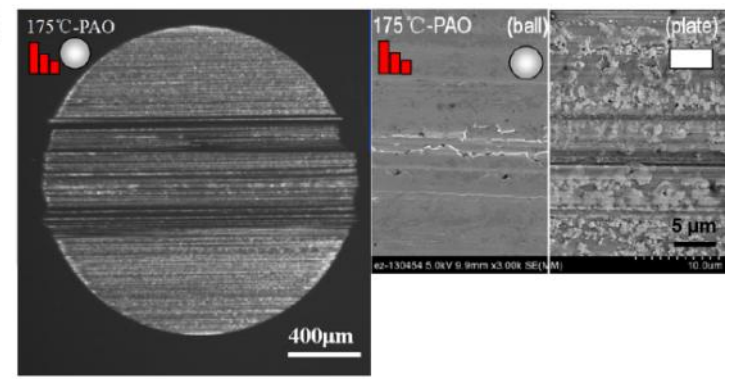

Fig. 3. Morphologies of worn surfaces tested in $0 \mathrm{~W} 30$ at (a) $23^{\circ} \mathrm{C}$, (b) $100^{\circ} \mathrm{C}$, and (c) $175^{\circ} \mathrm{C}$; (d) $0 \mathrm{~W} 30+1 \%$ $\mathrm{H}_{2} \mathrm{O}$ at $23^{\circ} \mathrm{C}$; PAO at (e) $23^{\circ} \mathrm{C}$, (f) $100^{\circ} \mathrm{C}$, and (g) $175^{\circ} \mathrm{C}$.

The EDS spectra of the ball wear scars generated in $0 \mathrm{~W} 30$ and PAO at 23,100 , and $175^{\circ} \mathrm{C}$ are shown in Figs. 4a and 4b. As expected, C, O, and Fe were identified in all spectra. The XPS core level spectra of $\mathrm{C}, \mathrm{O}$, and $\mathrm{Fe}$ for the worn surface tested in $0 \mathrm{~W} 30$ at $100^{\circ} \mathrm{C}$ are shown in Fig. $4 \mathrm{c}$. The spectra suggest that oxygen is present primarily bound in metal oxide(s) $(529.9 \mathrm{eV})$. Iron was in the following forms: metallic and cementite $\left(\mathrm{F}^{0}\right.$ overlapping with $\left.\mathrm{Fe}_{3} \mathrm{C}, 706.2 \mathrm{eV}\right)$ and oxidized $\left(\mathrm{Fe}^{2+} 707.9 \mathrm{eV}\right.$ and $\mathrm{Fe}^{3+}$ $709.7 \mathrm{eV})$. Carbon 1s spectra showed two main features: a peak at $282.6 \mathrm{eV}$ assigned to $\mathrm{C}-\mathrm{Fe}\left(\mathrm{Fe}_{3} \mathrm{C}\right)$ bonding and a peak at $284.8 \mathrm{eV}$ assigned to $\mathrm{C}-\mathrm{C}$ bonding.. 
For ball wear scars produced in both oils, the O:Fe ratio was highest at $100^{\circ} \mathrm{C}$, indicating the largest amount of oxides on the surface (protective film). This finding is consistent with the thick surface film observed in morphological examination (Fig. 3) and was correlated with the lowest wear. Low O:Fe ratios (or low amounts of oxides) appeared on ball wear scars tested at RT and at $175^{\circ} \mathrm{C}$, as shown in Figs. $4 \mathrm{a}$ and $4 \mathrm{~b}$. The addition of $1 \mathrm{wt} \% \mathrm{H}_{2} \mathrm{O}$ to the $0 \mathrm{~W} 30$ oil did not significantly alter the O:Fe ratio.
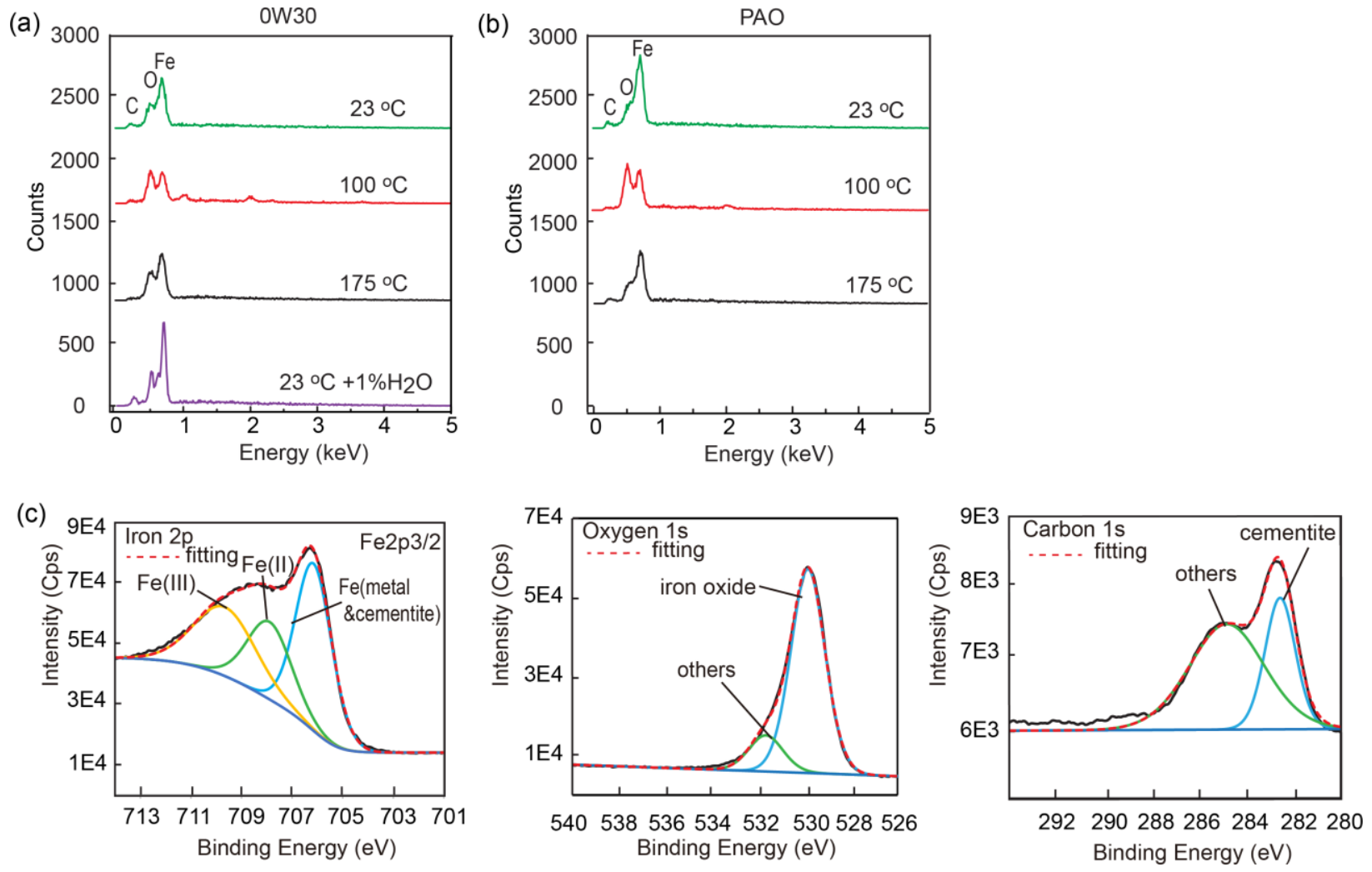

Fig. 4. Surface chemical analysis of selected ball wear scars. EDS spectra of worn balls tested at 23, 100, and $175^{\circ} \mathrm{C}$ in $0 \mathrm{~W} 30$ (a) and PAO (b); XPS core level spectra of key elements for the ball wear scar generated at $100^{\circ} \mathrm{C}$ in $0 \mathrm{~W} 30$.

\section{Discussion}

In this research, an interesting relationship was observed between the wear rates of balls and the testing temperatures. The wear rates decreased from RT to $75-100{ }^{\circ} \mathrm{C}$ and increased from 100 to $175^{\circ} \mathrm{C}$.

The wear that occurs during sliding contact is usually considered a mechanical process. Well-developed models of mechanical wear based on deformation and fracture have been reported [14]. 
Wear particles or debris in the contact zones can either reduce or increase wear [15], depending on the selection of materials, load, and removal of wear debris from the contact area. The test materials and lubricants used in these studies, such as carbon steels and base oils, were simple and common to simplify the tribochemical interactions at the interface.

Figure 5 illustrates the combined effects among the following three factors observed: (1) mechanical removal, which was directly related to oil viscosity; (2) protective surface film formation involving oxidation induced by oxygen dissolved in the oil, which was proportional to the oil temperature; and (3) additional beneficial oxidation induced by water dissolved in the oil, which was effective up to $100^{\circ} \mathrm{C}$. Each factor is further discussed below.

- With increasing temperature, oil viscosity dropped and protection from the oil was reduced. Hence, the mechanical removal rate increased.

- The presence of water supposedly increased the oil viscosity, thereby increasing the thickness of the oil film at the contact interface, as well as the metal surface oxidation [12]. At temperatures lower than $100^{\circ} \mathrm{C}$, the number of water molecules absorbed from the air into the oil increased with increasing oil temperature [16]. The oxidation of the rubbing metallic surfaces and wear debris was more rapid from $\mathrm{RT}$ to $100^{\circ} \mathrm{C}$ because of the higher temperature and the higher amount of dissolved moisture. Consequently, a thicker surface film with higher surface coverage formed at $100^{\circ} \mathrm{C}$, as was observed from both morphological examination (Fig. 3) and surface chemical analysis (Fig. 4). Metal-to-metal asperity contact was reduced by the oxide surface film, resulting in a lower wear rate (Fig. 2).

- At the test temperature range of 100 to $175^{\circ} \mathrm{C}$, water evaporated out of the lubricating oil. Under this condition, oxidation depended on the oil temperature and the oxygen dissolved in the oil (which was largely controlled by the temperature).

- Dissolved water in the oil seemed to promote oxidation to form the protective surface film, but an additional 1 wt $\%$ of water resulted in a higher wear rate, probably because of the co-existence of dissolved and emulsified water. The presence of emulsified water in oil is 
known to be detrimental $[10,11]$ and is believed to be responsible for the increased wear observed here.

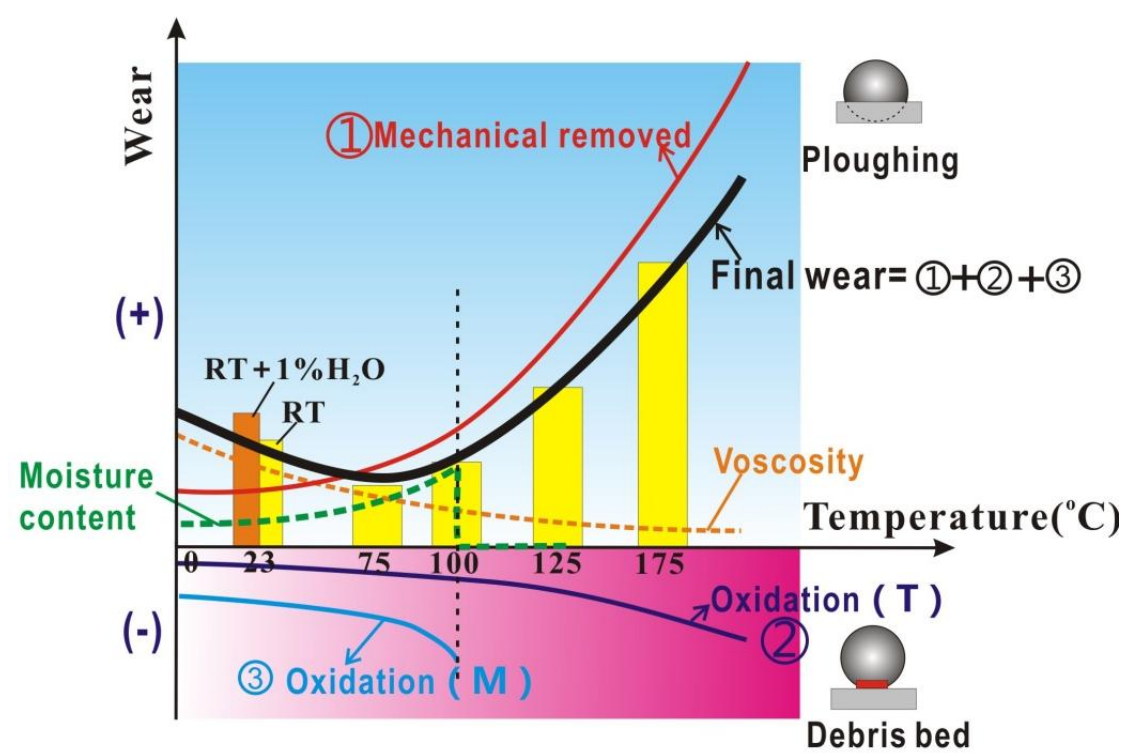

Fig. 5. Schematic diagram of wear mechanisms. The final wear is the cumulative effect of oil viscosity, oxide film formation, and oil water content.

\section{Summary}

Two base oils were used to lubricate a steel-steel reciprocating sliding contact at a temperature range of 23 to $175^{\circ} \mathrm{C}$. Notable observations can be summarized as follows:

(a) Generally, a higher oil temperature led to a higher COF because of the proportionally reduced oil viscosity, which led to more surface asperity collisions.

(b) The wear rates at $75-100^{\circ} \mathrm{C}$ were consistently the lowest. It was counterintuitive to observe a lower wear at $75-100^{\circ} \mathrm{C}$ than at $\mathrm{RT}$, because decreasing oil viscosity at a higher temperature was thought to control the wear behavior. Only when the temperature rose above $100^{\circ} \mathrm{C}$ did the wear rate become proportional to the oil temperature as expected. This clearly suggests that there are other significant factors than oil viscosity influencing the wear process upon temperature change.

(c) Wear scar morphology examination by OM and SEM and surface chemical analysis with EDS and XPS of selected ball wear scars revealed a surface film comprising metallic and oxide 
materials. The oxide content and surface coverage of the film appeared to be temperature dependent, and were highest at $100^{\circ} \mathrm{C}$ and low at 23 and $175^{\circ} \mathrm{C}-$ a trend correlating well with wear performance.

(d) The wear mechanism is proposed as combined effects among the following three factors: (1) mechanical removal, which was directly related to oil viscosity; (2) protective surface film formation involving oxidation induced by oxygen dissolved in oil, which was proportional to the oil temperature; and (3) additional beneficial oxidation induced by water dissolved in oil, which was effective up to $100^{\circ} \mathrm{C}$.

(e) Although dissolved water in oil could promote oxidation in forming the protective surface film, water above the saturation level (emulsion) seemed to be detrimental with regard to wear behavior.

\section{Acknowledgements}

The authors thank Drs. X.-g. Sun and H.M. Meyer III from ORNL for measuring water content in the oil, and discussing the XPS results, respectively. The authors also thank A.G. Bro from ExxonMobil for providing the PAO base oil and T. Daniels and J. Green from Chevron for providing the 0W30 base oil. This research was sponsored by the Vehicle Technologies Office, Office of Energy Efficiency and Renewable Energy, US Department of Energy. Dr. Z.-b. Cai was supported by the China Scholarship Council Study Abroad Fund.

Notice: This manuscript has been authored by UT-Battelle, LLC, under Contract No. DE-AC05-00OR22725 with the US Department of Energy. The United States Government retains and the publisher, by accepting the article for publication, acknowledges that the United States Government retains a non-exclusive, paid-up, irrevocable, world-wide license to publish or reproduce the published form of this manuscript, or allow others to do so, for United States Government purposes.

\section{References}


[1] X. Wang, K. Kato, K. Adachi, K. Aizawa. The effect of laser texturing of SiC surface on the critical load for the transition of water lubrication mode from hydrodynamic to mixed, Tribolo Int 34 (2001) 703-711.

[2] M. M. Khonsari, E. R. Booser. Applied Tribology: Bearing Design and Lubrication. John Wiley \& Sons, New York, NY, 2001.

[3] E. R. Booser. Circulating Oil Systems. Tribology Data Handbook. CRC Press, p. 404-412, 1997.

[4] Kuldeep K. Mistry, Ardian Morina, Anne Neville. A tribochemical evaluation of a WC-DLC coating in EP lubrication conditions, Wear 271 (2011) 1739-1744.

[5] A.M. Ashraful, H. H. Masjuki, M. A. Kalam, H. K. Rashedul, H. Sajjad, M. J. Abedin. Influence of anti-corrosion additive on the performance, emission and engine component wear characteristics of an IDI diesel engine fueled with palm biodiesel, Energ Convers Manage 87(2014) 48-57.

[6] C. Q. Yuan, Z. Peng, X. C. Zhou, X. P. Yan. Effects of temperature on sliding wear process under contaminated lubricant test conditions, Wear 257 (2004) 812-822.

[7] M. R. Sari, A. Haiahem, L. Flamand. Effect of lubricant contamination on gear wear, Tribol Lett, 27 (2007) 119-126.

[8] H. P. Bloch. Criteria for water removal from mechanical drive steam-turbine lube oils, Lubr Eng 36 (1980) 699-707.

[9] J. Fitch, S. Jaggernauth. MOISTURE-The second most destructive lubricant contaminate, and its effects on bearing life, P/PM Magazine (1994).

[10] M. RatoiSalagean, H. A. Spikes, H. L. Rieffe. Optimizing film formation by oil-in-water emulsions, Tribol T 40 (1997) 569-578.

[11] A. C. Eachus. The trouble with water, Tribol Lubr Technol (2005) 32-38.

[12] E. Harika, M. Helene, J. Bouyer, M. Fillon. Impact of lubricant contamination with water on hydrodynamic thrust bearing performance, Mec Ind 12 (2011) 353-359.

[13] P. A. Ramsey. A breath of fresh air, Machinery Lubrication Magazine (2001).

[14] G. W. Stachowiak. Wear: Materials, Mechanisms and Practice, Wiley, 2005. 
[15] M. Varenberg, G. Halperin, I. Etsion. Different aspects of the role of wear debris in fretting wear, Wear 252 (2002) 902-910.

[16] M. S. Whitten, K. A. Stelson. Determining water content at saturation for three common wind turbine gearbox oils: Mobilgear SHC XMP 320, AMSOIL EP Gear Lube ISO-320 and Castrol Optigear A320, ASME/BATH 2013 Symposium on Fluid Power and Motion Control, American Society of Mechanical Engineers, 2013. 